\title{
BEHAVIORAL LAW AND ECONOMICS E O USO DE ANIMAIS NA PESQUISA CIENTÍFICA
}

Juliana Lima de Azevedo ${ }^{33}$

Recebido em: 31/08/2018

Aprovado em: 24/10/2018

\begin{abstract}
RESUMO
Este artigo visa a verificar a aplicabilidade de algumas ideias da Behavioral Law and Economics ao processo de tomada de decisão no que concerne à utilização de animais na pesquisa científica, por meio do método dedutivo e amparado em pesquisa bibliográfica. A Behavioral Law and Economics é uma vertente da Análise Econômica do Direito que entende que a racionalidade é limitada e que o processo de decisão é influenciado por heurísticas e vieses. Por sua vez, o uso de modelos animais é uma prática antiga na ciência ocidental, cuja opção envolve aspectos científicos e morais. Quanto aos primeiros, o mais importante diz com a adequação de se transpor os resultados obtidos a partir da pesquisa realizada com animais para os seres humanos. No que tange aos segundos, o mais relevante considera a questão do sofrimento, tendo em conta que os animais são seres sencientes. Cotejando-se alguns fatores concebidos pela Behavioral Law and Economics com os aspectos envolvidos no processo de tomada de decisão pela utilização de animais na pesquisa científica, verifica-se que esse processo não é puramente racional, sofrendo influência de vieses que fazem com que o uso dos modelos animais se perpetue.
\end{abstract}

Palavras-chave: Behavioral Law and Economics. Animais. Pesquisa.

\section{INTRODUÇÃO}

Os animais vêm sendo utilizados na produção do conhecimento desde a Antiguidade Clássica pelo menos. A experimentação com animais é prática antiga que teve diferentes contornos ao longo dos séculos, em razão da relação estabelecida entre aqueles e os seres humanos, fundada no antropocentrismo, compreendido, sucintamente, como a perspectiva filosófica que atribui valor intrínseco apenas ao homem.

\footnotetext{
${ }^{33}$ Mestranda em Direito pela Universidade Federal do Rio Grande do Sul - UFRGS. Especialista em Direito Público pela Faculdade Meridional em parceria com a Escola Superior da Magistratura Federal - ESMAFE. Especialista em Direito Ambiental Nacional e Internacional pela UFRGS. Juíza de Direito vinculada ao Tribunal de Justiça do Rio Grande do Sul.
} 
Durante bastante tempo, o antropocentrismo foi fundamento suficiente para justificar as pesquisas com animais sem que se enfrentasse a questão do sofrimento daqueles seres, o que não era discutido. Todavia, a partir das ideias de Descartes, a vivissecção tornou-se prática corriqueira, uma vez que aquele filósofo sustentava que os animais não possuiriam alma, sendo apenas máquinas, insensíveis à dor e a outros sentimentos (DESCARTES, 2016, p. 95-96). Assim, negado o sofrimento e a senciência dos animais, não havia limites éticos a serem observados pelos pesquisadores. Por outro lado, apesar de ser a experimentação animal uma prática arraigada na ciência do mundo ocidental, é necessário perquirir se essa prática se assenta sobre argumentos racionais ou se decorre muito mais da tradição ou de outros fatores ou processos que não correspondem a um raciocínio consciente.

De outra banda, também a relação entre Direito e Economia é antiga e é possível afirmar que o diálogo entre esses dois ramos de conhecimento oferece uma grande contribuição em termos de soluções para questões atuais. A Análise Econômica do Direito ou Economia do Direito "pode ser definida de forma simples como a aplicação da teoria econômica (principalmente a teoria dos preços) e dos métodos estatísticos ao estudo da formação, estrutura, processos e impacto da lei e das instituições jurídicas" (MELO, 2016, p. 158). Os estudos de Law and Economics partem do pressuposto de que as pessoas agem racionalmente, de forma que responderão melhor a incentivos externos que induzam a certos comportamentos. Assim, propõe-se que seja realizada alguma avaliação ou análise econômica na formulação das normas jurídicas, de forma que a legislação seja mais eficiente. Trata-se de buscar a aplicação da metodologia utilizada na Economia - construção de modelos a partir de dados empíricos coletados na sociedade associados a teorias - ao Direito, cujo modelo ensinado nas faculdades tende a ser dogmático e abstrato (SZTAJN, 2005, p. 74-5).

Entretanto, uma vertente da Análise Econômica do Direito, a Behavioral Law and Economics preconiza que a racionalidade humana tende a ser limitada por uma série de desvios e heurísticas (SANTOLIM, 2017), ou seja, o pressuposto de que as pessoas agem racionalmente com vistas a obter melhores resultados para si é parcialmente afastado, na medida em que uma série de outros fatores passam a ser verificados no processo de tomada de decisão. Assim, elementos que agregam parcialidade ao raciocínio precisam ser considerados, tais como os hábitos, as tradições, o excesso de confiança entre outros. Da mesma forma, no que concerne aos julgamentos morais, o modelo social intuicionista sustenta a inexistência de um raciocínio puramente objetivo, afirmando haver, em vez disso, uma justificação $a$ posteriori de intuições rápidas e automáticas sobre temas da esfera moral.

Nesse contexto, orientado pelo método dedutivo e amparado em pesquisa 
bibliográfica, o presente artigo se propõe a verificar a aplicabilidade de algumas ideias da Behavioral Law and Economics ao processo de tomada de decisão no que concerne à utilização de animais na pesquisa científica, tanto por parte dos pesquisadores quanto por parte dos leigos, que, em tese, podem se beneficiar do produto obtido, considerando, ainda, os aspectos científicos e morais que estão imbricados na opção pelo uso dos modelos animais.

\section{SOBRE O PROCESSO DE TOMADA DE DECISÃO}

A utilização de animais na produção do conhecimento, ou seja, nas pesquisas científicas, tende a ser justificada com um argumento alegadamente racional no sentido de sua imprescindibilidade para o desenvolvimento da ciência e, em última instância, para o aprimoramento e preservação da vida humana.

Impende observar que, durante muito tempo, os filósofos atribuíram à razão a função de esclarecer os homens no sentido de dominarem suas paixões e emoções, a fim de levarem uma vida virtuosa. Entretanto, no século XVIII, alguns começaram a discutir alternativas ao racionalismo, dentre os quais destacou-se David Hume, que afirmava que os julgamentos morais derivam do sentimento e não da razão, a qual é um instrumento utilizado pela mente para obter e processar informações sobre os eventos ou relações entre objetos (HAIDT, 2001, p. 3). Hume dividia os raciocínios em duas classes, quais sejam, o raciocínio demonstrativo concernente às relações entre ideias - e o raciocínio moral - atinente às questões de fato e existência - e atribuía importância à experiência no entendimento humano. Para ele, os raciocínios acerca de questões de fato fundam-se na relação de causa e efeito e não são descobertos pela razão, mas sim pela experiência (HUME, 2009).

Nesse contexto, é possível considerar a aplicação do modelo intuicionista social - que se afasta do puro racionalismo -, bem como da Behavioral Law and Economics - uma derivação da Análise Econômica do Direito - sobre o processo de tomada de decisão no que tange à utilização de animais nas pesquisas científicas. De efeito, estudos comportamentais demonstraram que a racionalidade humana tende a ser limitada por uma séria de desvios e heurísticas, pois "segundo os behavioristas, os indivíduos, no mundo real, padecem de uma racionalidade e de um poder de escolha limitados" (SANTOLIM, 2017).

A partir de uma série de estudos realizados, referidos por Haidt, o modelo social intuicionista entende que as pessoas possuem intuições morais rápidas e automáticas e que, quando instadas a justificar tais intuições, buscam posteriormente fundamentos em teorias 
morais, criando, assim, a ilusão de um raciocínio objetivo. Além disso, existem elementos aptos a pôr em xeque a importância causal da razão. A um, a existência frequente de dois sistemas de processamento paralelamente em atuação quando alguém faz um julgamento ou resolve um problema: o de raciocínio e o intuitivo. A dois, avaliações feitas de forma automática pelos indivíduos. A três, julgamentos morais automáticos, usualmente feitos acerca de outras pessoas sem reflexão ou raciocínio consciente, a partir, por exemplo, do recurso a estereótipos. Demais disso, há duas espécies de motivos que aparentam direcionar o raciocínio de uma forma parcial, a saber, motivos relacionados à identificação e motivos de coerência. Os primeiros dizem respeito à influência causada pelas opiniões, julgamentos ou pontos de vista dos amigos e aliados, ou seja, concernem a um desejo de manutenção da harmonia e concordância dentro do grupo social ao qual o sujeito pertence. Os segundos, por seu turno, decorrem da construção de uma visão de mundo e de si próprio, a qual não deve ser ameaçada, sob pena de gerar uma contradição interna no indivíduo. Desse modo, as pessoas tendem a não buscar justificar exaustivamente suas crenças prévias (HAIDT, 2001).

Da mesma forma que a aplicação do modelo social intuicionista é relevante na tomada de decisões, é importante verificar outros elementos derivados dos estudos comportamentais. De efeito, a Análise Econômica do Direito pode ser concebida, na sua origem, como uma teoria comportamental, dado que considera as respostas dadas pelos atores às diretivas do sistema legal. Para tanto, foram importadas uma série de presunções da Economia sobre como as pessoas respondem aos incentivos, as quais são conhecidas como Teoria da Escolha Racional - sobre cuja definição não há consenso na doutrina, mas que pode ser entendida como uma presunção de que as pessoas agem de modo a maximizar sua utilidade esperada ou de que buscam maximizar seus próprios interesses -, a qual foi bastante útil nos seus primórdios. No entanto, na atualidade, há uma série de evidências experimentais que são incompatíveis com suas presunções, o que determina que outros elementos sejam considerados na análise das condutas. Pesquisas acerca do processo de tomada de decisão conjuntamente com a observação do que ordinariamente acontece sugerem que, muitas vezes, as pessoas não agem de modo a maximizar sua utilidade esperada, mas sim utilizam atalhos para decidir, em razão do custo de se processar todas as informações ou, mesmo, por limitações cognitivas. (KOROBKIN; ULEN, 2000).

Sobre o tema, pesquisas nas ciências comportamentais demonstraram que os indivíduos são sistematicamente conduzidos à parcialidade nas suas predições sobre os resultados prováveis de eventos (KOROBKIN; ULEN, 2000, p. 1085), em razão de problemas na forma como recebem, armazenam, acessam e processam as informações 
(KURAN; SUNSTEIN, 1999, p. 705). Destarte, outros fatores além dos pressupostos pela Teoria da Escolha Racional precisam ser também considerados por ocasião da análise do processo de decisão, tais como a disponibilidade, a representatividade, o excesso de confiança, a ancoragem e ajustamento e o efeito de moldura, por exemplo.

A heurística da representatividade diz com a tendência dos agentes a ignorar a probabilidade real de um evento acontecer, superestimando-a quando tal evento é típico ou representativo de um tipo de situação (SANTOLIM, 2017). Por seu turno, a heurística da disponibilidade é usada quando o agente superestima a relevância de determinados eventos ao custo de sua real probabilidade, ou seja, o agente acredita que um determinado evento é mais comum do que ele realmente é, porque está mais vívido em sua memória ou na das pessoas de suas relações (KOROBKIN; ULEN, 2000, p. 1086). Trata-se, portanto, de um atalho mental, por meio do qual a probabilidade percebida de um determinado evento é atrelada à facilidade com que esse evento é lembrado (KURAN; SUNSTEIN, 1999, p. 685). Por sua vez, o excesso de confiança concerne a um otimismo seletivo, ou seja, a crença do agente de que lhe sucederão eventos bons, enquanto eventos ruins acontecem aos demais (KOROBKIN; ULEN, 2000, p. 1091). Trata-se de um fator que se relaciona ao desvio referente à manutenção do status quo (SANTOLIM, 2017).

Além disso, releva observar que as pessoas tendem a repetir as condutas do passado, em razão de três fatores: hábitos, tradição e adições. Para o tema em comento - utilização de animais nas pesquisas - importa explicitar que os hábitos são utilizados para reduzir os custos de tomada de decisão, atuando como um instrumento de heurística, enquanto que a tradição tem um efeito consciente nas preferências individuais, relacionando-se com a manutenção do status quo (KOROBKIN; ULEN, 2000, p. 1113-4).

Demais disso, constata-se que as normas sociais também são um fator que pode afastar o agente da busca do seu próprio interesse no processo de escolha, compreendendo-se aquelas como sendo as atitudes sociais que especificam que comportamentos os agentes devem exibir. Nesse contexto, há situações em que a norma social impõe determinada conduta ao indivíduo, a qual não correspondente à atitude que conduziria à maximização do interesse dele. A adesão à norma social garante a ele a estima e aprovação dos demais, enquanto sua violação lhe custaria tal estima e aprovação. Ademais, pode a norma social estar internalizada na pessoa, de modo que, mesmo na ausência de outro membro do grupo, ela a obedece (KOROBKIN; ULEN, 2000).

Outro elemento a ser considerado são as cascatas de disponibilidade, definidas como um processo de formação de crença coletiva por meio do qual uma percepção expressa aciona 
uma reação em cadeia que fornece a essa percepção uma plausibilidade crescente através de sua disponibilidade no discurso público. Isso ocorre porque, em uma série de contextos envolvendo situações de risco, os indivíduos não dispõem de conhecimento direto e confiável, de modo que eles acessam as probabilidades por meio de heurísticas. Frequentemente, a heurística de disponibilidade é ampliada por sinais informacionais socialmente formatados pessoas com informações incompletas sobre certo assunto fundamentam suas crenças nas crenças aparentes de outras - e incentivos reputacionais - a motivação do sujeito para expressar a crença em algo consiste em obter aprovação social e evitar a desaprovação de seus pares - , ou seja, as pessoas tendem a acreditar em algo, porque outros acreditam ou fingem acreditar para evitar dano à sua reputação, de forma que é possível falar em cascatas informacionais e cascatas reputacionais (KURAN; SUNSTEIN, 1999).

Tais processos, que modelam o discurso público, usualmente alimentam-se um do outro e, sob determinadas condições, geram cascatas de disponibilidade que se espraiam e pioram percepções equivocadas. Dessa forma, aqueles que se utilizam das cascatas de disponibilidade buscam utilizá-las para promover suas causas. Atuando de forma egoísta ou altruísta, focam a atenção em eventos isolados e selecionam informações que dão suporte à interpretação que preferem, fazendo com que aqueles que questionam seus objetivos pareçam equivocados (KURAN; SUNSTEIN, 1999, p. 761).

Tais cascatas podem surgir com relação a qualquer assunto sobre o qual um número considerável de pessoas dispõe de conhecimento limitado. Demais disso, importa observar que as cortes não são imunes a esse mecanismo, porquanto também os julgadores estão sujeitos à heurística de disponibilidade, vulneráveis a informações parciais e incentivos reputacionais (KURAN; SUNSTEIN, 1999). É certo que Kuran e Sunstein atingiram suas conclusões a partir de pesquisas comportamentais realizadas nos Estados Unidos; no entanto, em que pese o sistema jurídico seja diferente, a utilização de ferramentas para auxiliar no raciocínio é fato comum a todos os seres humanos, o que, por evidente, há de ser aplicado também à classe dos juízes.

No tópico, importa, ainda, observar o papel exercido pelos meios de comunicação de massa, dado que estes buscam primordialmente aumentar sua audiência. Por tal razão, tendem a enfatizar perigos em detrimento de segurança, dar maior exposição a certos riscos do que a outros e tratar determinados riscos como especialmente sérios. Inobstante a mídia, em regra, apresente opiniões distintas sobre vários assuntos, essa diversidade pode ser ilusória, em razão da seletividade dos editores na escolha dos comentários transmitidos no sentido de apresentar pontos de vista coincidentes com os deles (KURAN; SUNSTEIN, 1999, p. 719-720). 


\section{ASPECTOS DE ORDEM CIENTÍFICA ACERCA DA UTILIZAÇÃO DE ANIMAIS NA PRODUÇÃO DE CONHECIMENTO}

A utilização de animais na produção do conhecimento é de longa data: na Antiguidade Clássica, o médico grego Galeno começou a usar animais sistematicamente em suas pesquisas e, desde então, a ciência da Experimentação Animal tem evoluído e se aperfeiçoado (RIVERA, 2006, p. 164). Hodiernamente, está disseminada na sociedade a ideia de que as pesquisas com animais são absolutamente necessárias para salvar vidas humanas, o que seria impeditivo de discussões acerca desses experimentos.

O uso de animais em pesquisas deve considerar sua importância para os seres humanos e a justificativa da própria experimentação científica nesse tipo de modelo (GOLDIM; RAYMUNDO, 1997, p. 09). A maioria dos testes pode ser enquadrada em duas categorias, que derivam de diferentes perspectivas filosóficas: in vivo ou in vitro. A primeira é a dos testes realizados dentro do organismo em animais vivos, a partir das ideias de Descartes, segundo o qual podemos aprender sobre reações biológicas a partir de modelos animais. Consiste no atual padrão em testes de toxicidade, adotado há muitas décadas. A categoria de testes in vitro, por seu turno, consiste na técnica de executar um determinado procedimento em um ambiente controlado fora de um organismo vivo. Essa categoria reconhece a autonomia do valor dos animais e rejeita a aproximação instrumental do seu uso para a biologia e fisiologia humanas, argumentando que os dados obtidos em testes in vivo não são suficientemente úteis quando aplicados à realidade humana (HESSLER, 2011, p. 71-2).

Nem todos os conhecimentos obtidos a partir dos modelos animais são plenamente transponíveis ao ser humano (GOLDIM; RAYMUNDO, 1997, p. 9), porquanto as diferenças anatômicas, orgânicas, biológicas, metabólicas, histológicas, genéticas e psíquicas existentes entre os animais humanos e os não-humanos fazem com que os dados obtidos a partir de experimentos com estes últimos possam ser perigosos se aplicados àqueles (CASTRO, 2006, p. 186). Ocorre que os animais - aí incluídos os humanos e os não-humanos - foram submetidos a pressões evolutivas muito diferentes, de forma que o arranjo do material genético de cada espécie também é distinto. Por tal razão, Brügger conclui pela inadequação dos modelos animais, ao fundamento de que falham no critério predictabilidade, de forma a não ser possível inferir nada prospectivamente, apenas retrospectivamente (BRÜGGER, 2008). Os conhecimentos obtidos a partir de animais podem ser estendidos aos homens, mas 
não em todas as situações, não sendo possível saber, aprioristicamente e com segurança, se o resultado obtido é aplicável a todos.

$\mathrm{Na}$ mesma linha, Hessler refere que a atual avaliação científica dos testes de toxicidade do Conselho Nacional de Pesquisa dos Estados Unidos da Academia Nacional de Ciências concluiu que os testes em animais são caros e demorados, não exigindo o uso de alternativas onde estas existam. Ademais, não trazem resultados suficientemente bons, embora milhões de animais sejam mortos nessas práticas todos os anos, sendo apontado, pela professora, que as teorias darwinistas sugerem que a realidade humana é melhor compreendida a partir de estudos comportamentais e outras aproximações, por meio de pesquisas em seres humanos, e pela vivissecção (HESSLER, 2011). Brügger, no mesmo sentido, lembra que diversos autores, principalmente os que atuam na área da saúde, consideram o uso dos modelos animais pouco eficiente, em razão do baixo nível de confiabilidade dos dados provenientes desses experimentos, o que estaria, inclusive, retardando o progresso da ciência e causando sérios problemas para a saúde humana (BRÜGGER, 2008).

Também Singer assevera que as pesquisas médicas, frequentemente, duram décadas e, ao fim, nada trazem de conclusivo, inovador ou útil, mas servem apenas para encobrir mera curiosidade intelectual. Em "Libertação animal", arrola vários casos de pesquisas que se estenderam por muitos anos, mediante o sacrifício de inúmeras vidas animais, e ao custo de grandes quantias, para que, ao final, a conclusão fosse no sentido da inadequação de transpor os resultados obtidos em modelos animais para os seres humanos. Um exemplo muito lembrado das consequências danosas da inadequada transposição dos resultados obtidos com o uso dos modelos animais para os seres humanos envolve a Talidomida. Esse medicamento foi amplamente testado em animais antes de ser liberado para o uso humano (SINGER, 2010); todavia, pouco tempo após sua introdução no mercado farmacológico, percebeu-se que produzia alterações genéticas graves nos fetos em formação, ocasionando a redução dos seus membros superiores ou inferiores (FIGUEIREDO, 2012, p. 133).

Ademais, observa Singer, a título de exemplo, que no caso da ligação entre o consumo de tabaco e o câncer de pulmão, sua prova decorreu de dados oriundos de observações clínicas realizadas em seres humanos. Inobstante esse fato, dezenas de milhares de animais foram forçados a inalar fumaça de tabaco durante meses ou anos para tentar comprovar tal ligação (SINGER, 2010, p. 129).

Nesse contexto, verifica-se que a base científica para a utilização de animais nas pesquisas de medicamentos de forma não é tão sólida quanto apregoado por seus defensores; 
ao contrário, os aspectos acima apontados indicam que o uso indiscriminado dos modelos animais é, do ponto de vista científico, questionável.

\section{ASPECTOS DE ORDEM MORAL ACERCA DA UTILIZAÇÃO DE ANIMAIS NA PRODUÇÃO DE CONHECIMENTO}

Descartes, a partir de um ponto de vista mecanicista, sustentou que o corpo seria como uma máquina e que os organismos vivos não teriam a condição de seres conscientes, não sendo dotados de alma (DESCARTES, 2016). Essa ideia influenciou extremamente o pensamento moderno e o método científico utilizado até a atualidade, em especial, na relação do homem com o animal, de vez que aquele passou a compreender este ser vivo como o "animal-máquina", negando-lhe valor intrínseco e inaugurando a separação entre ser humano e natureza que marca a abordagem científica em quase todas as áreas do conhecimento, como observam Ingo Sarlet e Tiago Fensterseifer (SARLET; FENSTERSEIFER, 2012, p. 66).

Descartes compara a natureza que opera nos animais com o mecanismo de um relógio e aduz que a máquina, que é o corpo de cada animal, é incomparavelmente melhor ordenada e com movimentos mais admiráveis do que qualquer uma das feitas pelo homem, uma vez que feita pelas mãos de Deus. Entretanto, sendo máquinas, seriam insensíveis à dor e a outros sentimentos (DESCARTES, 2016, p. 94). O pensamento cartesiano permitiu a utilização dos animais na ciência de maneira indiscriminada e destituída de qualquer consideração ética.

Em 1959, surgiu a primeira publicação sobre aspectos éticos da utilização de animais que teve repercussão considerável, qual seja, The principles of Humane Experimental Technique, escrito por William Russell e Rex Burch. Na obra, seus autores fixam princípios para guiar as pesquisas, por meio da utilização dos três Rs na pesquisa com animais: replace, reduce e refine (substituição, redução e refinamento). A proposta não é a abolição dos modelos animais, mas sim uma adequação no sentido de humanizar a experimentação (GOLDIM; RAYMUNDO, 1997, p. 07). Os principais objetivos do conceito consistem na otimização, sob o prisma quantitativo, do número de animais usados e sua substituição sempre que possível e, sob o prisma qualitativo, na humanização dos procedimentos (TRÉZ, 2015, p. 83).

O primeiro $\mathrm{R}$ - replace - significa que a substituição do uso de animais por métodos alternativos, tais como testes in vitro, modelos matemáticos, simulações por computador, dentre outros, deve ser estimulada. O segundo pilar do princípio é a redução do número de 
animais utilizados nas pesquisas, a fim de que a mesma qualidade de informações científicas possa ser alcançada com o uso de menos animais. Assim, devem ser utilizados apenas a quantidade necessária para fornecer resultados estatísticos significativos aperfeiçoado (RIVERA, 2006, p. 175). O terceiro pilar consiste no refinamento das técnicas utilizadas, aperfeiçoando a eficiência da experimentação, de modo a minimizar a dor e o sofrimento nos animais, o que inclui cuidados de analgesia e assepsia nos períodos pré, trans e pósoperatório, além de questões metodológicas e estatísticas que permitem analisar dados obtidos em amostras progressivamente menores (GOLDIM; RAYMUNDO, 1997, p. 11). Por tal razão, apenas pessoas bem treinadas devem usar animais, devendo ser priorizados materiais e técnicas menos invasivos aperfeiçoado (RIVERA, 2006, p. 176).

Entretanto, embora o princípio dos 3Rs tenha representado um avanço para a utilização de modelos animais a partir de critérios éticos, ${ }^{34}$ tal princípio é insuficiente para justificar o uso de animais na produção do conhecimento, de vez que o sofrimento é uma característica intrínseca à maioria das pesquisas com animais. A um, o princípio não representa uma mudança de paradigma, dado que os animais enquanto cobaias não são alvo

\footnotetext{
${ }^{34}$ O princípio dos 3 Rs foi adotado pela Lei n. 11.794/08, que regulamenta o inciso VII do § $1^{\circ}$ do art. 225 da Constituição Federal, estabelecendo procedimentos para o uso científico de animais, in verbis:

Art. 14. O animal só poderá ser submetido às intervenções recomendadas nos protocolos dos experimentos que constituem a pesquisa ou programa de aprendizado quando, antes, durante e após o experimento, receber cuidados especiais, conforme estabelecido pelo CONCEA.

$\S 1$ - $\mathrm{O}$ animal será submetido a eutanásia, sob estrita obediência às prescrições pertinentes a cada espécie, conforme as diretrizes do Ministério da Ciência e Tecnologia, sempre que, encerrado o experimento ou em qualquer de suas fases, for tecnicamente recomendado aquele procedimento ou quando ocorrer intenso sofrimento.

$\S 2^{\circ}$ Excepcionalmente, quando os animais utilizados em experiências ou demonstrações não forem submetidos a eutanásia, poderão sair do biotério após a intervenção, ouvida a respectiva CEUA quanto aos critérios vigentes de segurança, desde que destinados a pessoas idôneas ou entidades protetoras de animais devidamente legalizadas, que por eles queiram responsabilizar-se.

§ 3- Sempre que possível, as práticas de ensino deverão ser fotografadas, filmadas ou gravadas, de forma a permitir sua reprodução para ilustração de práticas futuras, evitando-se a repetição desnecessária de procedimentos didáticos com animais.

$\S 4$ o O número de animais a serem utilizados para a execução de um projeto e o tempo de duração de cada experimento será o mínimo indispensável para produzir o resultado conclusivo, poupando-se, ao máximo, o animal de sofrimento.

$\S 5$ o- Experimentos que possam causar dor ou angústia desenvolver-se-ão sob sedação, analgesia ou anestesia adequadas.

$\S 6^{0}$ Experimentos cujo objetivo seja o estudo dos processos relacionados à dor e à angústia exigem autorização específica da CEUA, em obediência a normas estabelecidas pelo CONCEA.

$\S 7$ - É vedado o uso de bloqueadores neuromusculares ou de relaxantes musculares em substituição a substâncias sedativas, analgésicas ou anestésicas.

$\S 8$ o É vedada a reutilização do mesmo animal depois de alcançado o objetivo principal do projeto de pesquisa.

$\S 9$ o Em programa de ensino, sempre que forem empregados procedimentos traumáticos, vários procedimentos poderão ser realizados num mesmo animal, desde que todos sejam executados durante a vigência de um único anestésico e que o animal seja sacrificado antes de recobrar a consciência.

$\S 10$. Para a realização de trabalhos de criação e experimentação de animais em sistemas fechados, serão consideradas as condições e normas de segurança recomendadas pelos organismos internacionais aos quais o Brasil se vincula.
} 
de qualquer consideração moral. A dois, não provê um método para determinar se um experimento é social ou cientificamente necessário, além de ser de aplicação duvidosa para novas e emergentes tecnologias (HESSLER, 2011, p. 79). A três, recebe severas críticas por parte dos defensores dos animais, que observam que sua aplicação legitima a experimentação animal em vez de propor sua substituição, admitindo o simples refinamento das experiências e a mera redução dos animais usados (FEIJÓ; SANTOS; GREY, 2010, p. 157).

No ponto, importa lembrar que os testes de toxicidade - desenvolvidos na década de 1920 e utilizados para determinar quão venenosa é uma dada substância - tendem a ser extremamente cruéis aos animais. O teste de toxicidade aguda mais conhecido é o DL $50-$ dose letal para 50 por cento - a quantidade de substância que matará metade dos animais do estudo. A morte pode ser provocada pelo volume de substância engolido ou pela alta concentração. Outro teste bastante usado é o Draize, para cosméticos e outras substâncias. Desenvolvido em 1949, por meio desse teste, determinada substância é colocada nos olhos de animais - geralmente, coelhos - que são postos em dispositivos imobilizadores, que mantêm apenas suas cabeças na parte externa do aparelho (SINGER, 2010).

Conforme Peter Singer, a utilização de animais na ciência e no ensino é pautada pelo especismo, uma vez que, na imensa maioria dos casos, os pesquisadores sequer se importam em justificar porque a realização de um dado experimento é necessária, tampouco em que ele pode beneficiar a espécie humana. Ele ainda adverte que muitos cientistas provocam dor aguda e profundo sofrimento psíquico sem a mais remota perspectiva de benefícios ao homem ou a quaisquer outros animais. Procedimentos são repetidos inúmeras vezes, embora os resultados já sejam conhecidos, e pesquisas são realizadas com muito pouca variação entre si, desperdiçando vidas animais, sem nenhuma preocupação ética (SINGER, 2010, p. 33). O mesmo argumento é esposado por Francione, que observa que "os experimentadores usam os animais para todo tipo de propósitos triviais que não podem ser considerados necessários em nenhum sentido coerente" (FRANCIONE, 2013, p. 94).

Veja-se que um dos fundamentos usados pelos que defendem os modelos animais é justamente a existência de semelhanças entre humanos e outros animais, fator esse que é ignorado, contudo, na abordagem da questão do sofrimento. A experimentação animal não estimula o respeito pela vida nos estudantes, tampouco nos pesquisadores; ao contrário, tende a torná-los insensíveis ao sofrimento alheio, e, por via de consequência, também ao sofrimento humano. Sobre a questão da sensibilidade animal, importa lembrar a manifestação do Min. Francisco Rezek, relator do RE 153.531/SC - originário de uma ação civil pública ajuizada contra o Estado de Santa Catarina com o escopo de determinar que aquela unidade 
coibisse a farra do boi no seu território - que, em seu voto, afirmou que "com a negligência no que se refere à sensibilidade dos animais anda-se meio caminho até a indiferença a quanto se faça a seres humanos" (BRASIL, 2017).

Além disso, os modelos animais também são mantidos por razões econômicas, porquanto há uma indústria que sobrevive da utilização dos animais nas ciências: a maioria dos animais utilizados nos experimentos são criados e vendidos por grandes corporações (FRANCIONE, 2013, p. 95), com atuação em larga escala e movimentando recursos financeiros expressivos. A experimentação animal dá origem à comercialização de uma série de produtos, tais como os próprios animais, equipamentos, revistas especializadas etc. Veja-se que as indústrias farmacêuticas estão concentradas em países desenvolvidos e demonstram compromisso com a lucratividade, olvidando-se, por vezes, de que a demanda por medicamentos decorre do exercício do direito à saúde, que se sobrepõe a outros interesses (FROTA MONT’ALVERNE.; ALMEIDA DE ANDRADE, 2013).

Da mesma forma, conforme Singer, há várias pesquisas que existem apenas para justificar o numerário percebido de órgãos de fomento à pesquisa ou de indústrias. Quando a experimentação com animais se torna o padrão aceito de pesquisa em um certo campo, o processo passa a se autorreforçar, uma vez que dele decorrem as publicações, promoções, prêmios e bolsas para os pesquisadores, incentivando-os a prosseguir utilizando modelos animais nas suas carreiras (SINGER, 2010).

Ademais, a utilização dos modelos animais também resta assentada na alegação de que os animais não seriam sujeitos, mas mero objetos, razão pela qual, por evidente, não podem titularizar direitos, dentre os quais, o direito à vida e à integridade física.

Cabe observar que os conceitos existem a partir de uma dada compreensão histórica e cultural, não sendo, dessa forma, condições naturais dos seres humanos. Basta lembrar que, há menos de duzentos anos, os escravos não eram considerados sujeitos de direito, mas meras coisas, passíveis de apropriação. Da mesma forma, num passado recente, às mulheres eram negados uma série de direitos, tais como o direito de votar. Por outro lado, há seres despossuídos dos atributos que seriam pressupostos da condição de sujeitos de direito, mas que recebem essa condição a partir da legislação, por exemplo, as pessoas jurídicas (RODRIGUES, 2008, p. 188-9).

Nesse contexto, importa esclarecer que, hodiernamente, há autores que entendem que também os animais não-humanos devem ser inseridos numa comunidade moral ou, ao menos, devem ter seus interesses considerados.

Assim, Peter Singer propõe a extensão do princípio básico da igualdade entre os 
animais humanos para os animais não-humanos não no sentido de que lhes seja conferido tratamento igual ou idêntico, mas sim igual consideração. A senciência - capacidade de um ser vivo sentir dor ou prazer - é que lhe confere consideração moral. Destarte, não haveria justificativa moral para deixar de levar em conta o sofrimento (ou prazer) sentidos por um animal não-humano, sendo irrelevante a natureza do ser para tal consideração, tendo em conta o princípio da igualdade (SINGER, 2010, p. 24).

De outra banda, Tom Regan afirma que os animais humanos e não-humanos são sujeitos de uma vida, de modo a merecer consideração moral e ser titular de direitos (REGAN, 2004, p. 51). Dessa forma, por enquadrarem-se nessa categoria, os animais são protagonistas do destino de suas vidas, as quais não podem ser tomadas como mero objeto (SARLET; FENSTERSEIFER, 2012, p. 74-5). Os direitos por ele defendidos são os direitos morais básicos, atribuíveis a todos sem discriminações atinentes à cor da pele, à nacionalidade, ao gênero ou à espécie (REGAN, 2004, p. 39).

No ponto, Feijó lembra que o conceito kantiano de dignidade - basilar nos Direitos Humanos - é objetivo e reducionista, restringindo tal atributo aos seres humanos. Propõe, em contrapartida, que a dignidade seja conceituada de forma subjetiva, sendo ampliada por meio da aceitação do binômio dignidade/respeito, de modo a abarcar outros seres vivos, os quais também são participantes da biosfera. Assevera, por fim, que o reconhecimento da dignidade do animal não-humano de forma alguma vem em prejuízo do animal humano, nos seguintes termos:

Em relação aos animais não-humanos, especificamente, podemos dizer que a dignidade animal residiria no fato de o animal ser portador de um valor, talvez intrínseco, e, em função disso, ter interesse em não ser agredido. Tratar bem o animal não-humano e preocupar-se com sua integridade ampliam a consciência e a esfera de consideração moral humana e outorga uma dignidade subjetiva não padronizada a formas não padronizadas de alteridade (FEIJÓ, 2008, p. 143)

No mesmo sentido, Sarlet e Fensterseifer asseveram que a norma do artigo 225, $\S 1^{\circ}$, VII, da Constituição Federal brasileira ${ }^{35}$ - ao enunciar expressamente a vedação de práticas que provoquem a extinção de espécies ou submetam os animais a crueldade - indica o reconhecimento de valor intrínseco às formas de vida não-humanas por parte do constituinte

\footnotetext{
35 Art. 225. Todos têm direito ao meio ambiente ecologicamente equilibrado, bem de uso comum do povo e essencial à sadia qualidade de vida, impondo-se ao Poder Público e à coletividade o dever de defendê-lo e preservá-lo para as presentes e futuras gerações.

$\S 1^{\circ}$ Para assegurar a efetividade desse direito, incumbe ao Poder Público:

[...]

VII - proteger a fauna e a flora, vedadas, na forma da lei, as práticas que coloquem em risco sua função ecológica, provoquem a extinção de espécies ou submetam os animais a crueldade.
} 
originário, que determina, inclusive, sua proteção contra a ação humana. Há, destarte, a consagração normativa de uma tutela da vida em geral numa perspectiva concorrente e interdependente em relação à vida humana, e não meramente instrumental a esta (SARLET; FENSTERSEIFER, 2012, p. 79).

Sobre o tema, imprescinde referir o julgamento da Ação Direta de Inconstitucionalidade n. 4983, que declarou a inconstitucionalidade da Lei n. 15.299/2013, do Estado do Ceará, que regulamentava a vaquejada como prática desportiva e cultural naquela unidade federativa. Em seu voto, o Min. Roberto Barroso observou que a norma do art. 225, § $1^{\circ}$, inciso VII, da Carta Maior "protege os animais contra a crueldade não apenas como função de tutela de outros bens jurídicos, mas como um valor autônomo" e que "o sofrimento animal importa por si só, independentemente do equilíbrio do meio ambiente, da sua função ecológica ou de sua importância para a preservação da espécie”. Na mesma linha, a Min. Rosa Weber asseverou que a Constituição brasileira confere valor intrínseco às formas de vida não humanas, os seres sencientes, afirmando que a norma do dispositivo supracitado representa a superação da limitação antropocêntrica, possuindo matriz biocêntrica. Aduziu, ainda, que "os animais possuem uma dignidade própria que deve ser respeitada". No mesmo sentido, esclareceu o Min. Ricardo Lewandowski que faz interpretação biocêntrica do multicitado artigo 225, uma vez que "é preciso respeitar todos os seres vivos em sua completa alteridade e complementariedade".

Assim, é possível constatar que, tanto na doutrina quanto na jurisprudência, a utilização de animais nas pesquisas científicas é passível de questionamentos de ordem moral.

\section{A DECISÃO PELO USO DE ANIMAIS NA EXPERIMENTAÇÃO}

Como alhures referido, durante muito tempo a razão reinou soberana no pensamento ocidental, dominando tanto as ciências humanas quanto as ciências duras. No entanto, estudos comportamentais demonstraram que os seres humanos, no mundo real, possuem uma racionalidade limitada por desvios e heurísticas que influenciam diretamente seus julgamentos e decisões. Assim, as limitações cognitivas do ser humano e a incerteza sobre as consequências de um ato ou das probabilidades dos possíveis resultados podem conduzir à complexidade e/ou à ambiguidade no processo de tomada de decisão, de modo que os indivíduos - sejam eles os pesquisadores ou as pessoas que, em tese, podem se beneficiar das pesquisas realizadas - não maximizem a utilidade esperada ao decidir pelo uso de um modelo 
animal ou por um produto que foi desenvolvido a partir da experimentação com animais.

Por outro lado, o método cartesiano ainda é considerado o método das ciências duras por excelência, havendo pouco questionamento entre a maioria dos profissionais dessas áreas sobre as implicações de sua adoção. Aqueles que ousam opor-se ao mito da objetividade da ciência e à crença cartesiana da certeza do conhecimento que fundamentam a utilização dos animais nas pesquisas "são encarados, pela comunidade científica, como ignorantes e inimigos do progresso da medicina". Demais disso, como a ideia de que as experiências com animais não podem ser substituídas por outros métodos, sob pena de prejuízo à pesquisa, está cristalizada na imprensa, que forma a opinião pública, a tentativa de discutir a questão é vista, em regra, como manifestação de pessoas que não conhecem o assunto (CASTRO, 2006, p. 177-8).

Todavia, cabe lembrar que, considerando os estudos que embasaram a concepção do modelo social intuicionista, a importância causal da razão não é intangível, a partir da constatação da existência frequente de dois sistemas de processamento paralelamente em atuação quando alguém faz um julgamento ou resolve um problema - o de raciocínio e o intuitivo - e das avaliações feitas de forma automática pelos indivíduos, considerando a existência de duas espécies de motivos que tendem a direcionar o raciocínio de forma parcial, relacionados à identificação do indivíduo com seu grupo e à coerência com a visão de mundo por ele construída. Assim, cabe perquirir se a opção pelo modelo animal, no que concerne às implicações morais, não é decorrência de um raciocínio objetivo e consciente, mas sim possivelmente das intuições morais rápidas e automáticas, referidas por Haidt no primeiro capítulo, tendo em vista os aspectos dessa ordem envolvidos na utilização de animais nas pesquisas de medicamentos.

Além disso, consoante já enunciado, os hábitos e tradições conduzem as pessoas a repetir as condutas do passado, de forma quase automática. Desse modo, considerando que a experimentação animal é uma prática milenar na ciência, a sua perpetuação pelos pesquisadores pode ser concebida como um instrumento de heurística por eles utilizado para reduzir os custos da tomada de decisão - que poderia envolver, por exemplo, um método alternativo ao modelo animal na pesquisa realizada - consubstanciado num hábito. Da mesma forma, muitos pesquisadores prosseguem no uso dos modelos animais pela tradição desse modelo nas ciências duras, mantendo, assim, o status quo. Quanto ao possível beneficiário do resultado da pesquisa, pode-se lembrar também do desvio referente à manutenção do status quo é o excesso de confiança, o otimismo seletivo - crença de que lhe sucederão eventos bons, enquanto eventos ruins acontecem aos demais - manifestado na utilização dos fármacos que 
foram desenvolvidos nas pesquisas com animais sem ser verificado se a transposição dos resultados é adequada ao organismo humano. Veja-se que as consequências catastróficas da prescrição indiscriminada da Talidomida poderiam ter sido evitadas ou, ao menos, diminuídas se os pesquisadores e médicos houvessem considerado, com brevidade, que as pesquisas realizadas com os animais não estavam fornecendo resultados passíveis de serem transpostos para as pessoas, o que denota que possivelmente também estavam eles imbuídos de excesso de confiança.

Do mesmo modo, também a aplicação das heurísticas da disponibilidade - atalho mental, por meio do qual a probabilidade percebida de um determinado evento é atrelada à facilidade com que esse evento é lembrado - e da representatividade - tendência dos agentes a ignorar a probabilidade real de um evento acontecer, superestimando-a quando tal evento é típico ou representativo de um tipo de situação - devem ser consideradas. Veja-se que o argumento mais comumente utilizado pelo leigo para justificar a utilização de animais em pesquisas é o de que o sacrifício da vida desses seres é necessário para melhorar ou salvar a vida humana, a partir dos fármacos que serão desenvolvidos com essa finalidade (REGAN, 2004, p. 159). Essa avaliação ou julgamento tende a ser feito a partir da própria experiência do agente ou de alguém próximo com a situação de doença ou de algum caso que tenha sido bastante veiculado na mídia ou nas redes sociais, fatores que fazem com que tais fatos próximos - pela experiência ou pela divulgação - sejam considerados como expressão da indispensabilidade do uso dos modelos animais.

No que concerne ao discurso esposado pelo agente, é necessário lembrar que a ciência tende a ser antropocêntrica, ou seja, toma como centro o homem, no sentido de que existe e se fundamenta na melhoria das condições de vidas dos seres humanos. Assim, é preciso levar em conta a força exercida pelas normas sociais e por eventuais cascatas de disponibilidade. As normas sociais, como já explanado, são entendidas como sendo as atitudes sociais que especificam que comportamentos os agentes devem exibir e cuja adesão garante a eles a estima e aprovação dos demais, enquanto sua violação lhes custaria tal estima e aprovação. Pelas cascatas reputacionais, as pessoas fingem acreditar em algo para evitar danos à sua reputação, obtendo, com isso, aprovação social e evitando a desaprovação de seus pares. Pelas cascatas informacionais, pessoas com informações incompletas sobre certo assunto fundamentam suas crenças nas crenças aparentes de outras, isto é, acreditam em algo, porque outros acreditam. A partir da aplicação desses dados, pode-se compreender a possível razão pela qual o questionamento acerca dos aspectos éticos de se utilizar a vida de outros seres como instrumento e de se desconsiderar o sofrimento dos animais utilizados não encontra eco 
em todos os grupos sociais.

Demais disso, é imperioso lembrar o papel exercido pelos meios de comunicação de massa na propagação de determinadas ideias, notadamente no que concerne ao tratamento midiático dispensado a certos riscos, ora enfatizando-os, em detrimento de sua probabilidade real, ora subestimando-os, com o escopo de obter maior audiência. Como pertinentemente observado por Tom Regan, a mídia usualmente está presente quando um ato ilícito é realizado por algum ativista da causa ambiental, enquanto um protesto pacífico pela mesma causa tende a ser ignorado, uma vez que o primeiro é sensacionalista, mas o segundo não o é. O filósofo ainda assevera que a mídia é alimentada por dados repassados pelos setores de relações públicas das maiores indústrias que se utilizam de animais, tais como as que lidam com carnes, peles, pesquisa biomédica e entretenimento com animais (REGAN, 2004, p. 11). Por essa razão, a função que os meios de comunicação social exercem nas cascatas de disponibilidade é fundamental, considerando que possuem meios de divulgação muito mais amplos do que as pessoas comuns. Como já referido, aqueles que se utilizam das cascatas de disponibilidade buscam utilizá-las para promover suas causas e denegrir as opiniões contrárias, de modo que focam a atenção em eventos isolados e selecionam informações sobre as quais se assenta a interpretação que preferem.

A partir dos argumentos acima expendidos de forma exemplificativa, percebe-se que o processo de tomada de decisão pertinente ao uso de animais na pesquisa científica também é possivelmente influenciado pelos vieses analisados nos estudos behavioristas, tanto por parte dos pesquisadores quanto da parte dos leigos que são os potenciais beneficiários das pesquisas, afastando-se, destarte, do raciocínio objetivo e imparcial.

\section{CONSIDERAÇÕES FINAIS}

Como exaustivamente referido ao longo do texto, a prática da experimentação animal é muito antiga, sendo que, durante um longo período, o antropocentrismo foi fundamento bastante em si mesmo para justificá-la, sem que se enfrentasse ou negasse a questão do sofrimento animal. Todavia, a mudança de paradigma foi estabelecida com Descartes, que arrancou dos animais qualquer consideração ética que lhes poderia ser aplicada, a partir de sua ideia do animal-máquina, destituído de alma e sentimentos e incapaz de sofrer. Assim, houve um grande impulso ao uso dos modelos animais. Na atualidade, o argumento usualmente utilizado pelos que defendem as pesquisas com animais, tanto cientistas quanto leigos, é no 
sentido de que elas seriam imprescindíveis para o progresso da ciência, de modo que vidas humanas sejam salvas ou, pelo menos, melhoradas. Trata-se, alegadamente, de uma decisão embasada na racionalidade.

Por outro lado, estudos realizados pela Behavioral Law and Economics demonstram que, na realidade, os indivíduos não agem de forma totalmente racional. Ao contrário, o raciocínio dos seres humanos é afetado por desvios e heurísticas, que não podem ser desconsiderados quando se analisa o processo de tomada de decisão. Por tal razão, quando se busca compreender os julgamentos morais, é preciso levar em conta as ideias do modelo intuicionista social, que entende que aqueles são feitos a partir de rápidas intuições, seguidas de um raciocínio posterior que busca justificá-los. Da mesma forma, é importante verificar outros elementos derivados dos estudos comportamentais e que tendem a conduzir as decisões e escolhas de forma parcial. Tais desvios são a disponibilidade, a representatividade, o excesso de confiança, o desvio retrospectivo, a ancoragem e ajustamento e o efeito de moldura. Demais disso, no que concerne à coletividade, outro elemento a ser considerado são as cascatas de disponibilidade, que são um processo de formação de crença coletiva que decorre da aplicação de heurísticas em contextos envolvendo situações de risco em que as pessoas não dispõem de conhecimento direto e confiável sobre o tema. Assim, surgem cascatas informacionais ou reputacionais, as primeiras fundamentadas nas crenças aparentes de outras pessoas quando os indíviduos não possuem informações completas sobre o assunto e as segundas embasadas na vontade de obter aprovação social dos pares. Nesse contexto, considerando os elementos trazidos pela Behavioral Law and Economics, buscou-se verificar se a opção pelos modelos animais é efetivamente uma decisão racional. Sobre o tema, há aspectos de duas ordens a serem considerados: científicos e morais.

Constatou-se que a pesquisa que utiliza animais precisa levar em conta dois requisitos, quais sejam, a importância da pesquisa para os seres humanos e a justificativa do uso do modelo. Ademais, além dos testes in vivo, que se fundamentam no trabalho de Descartes e que se consubstanciam na utilização dos modelos animais, é possível realizar testes in vitro, que consistem em executar um determinado procedimento de forma controlada fora de um organismo vivo. Verificou-se que, em muitas situações, os primeiros não oferecem resultados confiáveis, além de submeterem os animais a sofrimento e morte. De efeito, a extrapolação dos dados obtidos a partir dos modelos animais para os seres humanos nem sempre é possível, sendo inviável saber aprioristicamente e com segurança se o resultado obtido na experimentação com animais pode ser transposto para as pessoas.

No que concerne aos aspectos morais, as ideias cartesianas conduziram à utilização de 
animais na ciência desprovida de qualquer consideração ética, notadamente no que tange ao sofrimento por eles experimentado, o que é uma característica intrínseca à imensa maioria das pesquisas com animais. Ademais, não se pode esquecer que os modelos animais também são mantidos por questões puramente financeiras, porquanto envolvem quantias bastante expressivas de numerário em uma série de setores da economia. Apesar disso, na atualidade, vários doutrinadores entendem que os animais devem ter seus interesses considerados ou precisam ser inseridos numa comunidade moral, ideias que gradualmente se estão imiscuindo nas cortes, dado que, no julgamento da ADI 4.983, três ministros do STF expressamente declararam que a norma constitucional que veda a crueldade contra animais tem caráter biocêntrico.

Vistos os aspectos científicos e morais atinentes ao uso de animais na pesquisa, constatou-se que se pode pensar na decisão pelo uso dos modelos animais a partir de alguns elementos trazidos pelos estudos behavioristas. É possível aplicar o modelo social intuicionista aos julgamentos morais concernentes à utilização de animais na produção do conhecimento. Ademais, é consabido que os modelos animais são usados há séculos, de modo que constituem uma tradição nas ciências duras. Além disso, no nível individual, a opção do pesquisador pode decorrer de um hábito, o que reduziria o custo temporal de se dedicar a buscar um método alternativo. Demais disso, o excesso de confiança se manifesta na transposição irrefletida dos resultados obtidos a partir do uso dos modelos animais para o organismo humano e o desvio retrospectivo, por sua vez, pode ser considerado em eventual responsabilização civil em decorrência da extrapolação inadequada de dados.

Outras aplicações das ideias behavioristas podem ser pensadas no que concerne à utilização de animais nas pesquisas, dado que o rol acima é meramente exemplificativo. No entanto, uma conclusão é impositiva: a opção pelo uso de modelos animais não é pautada apenas na racionalidade, sendo influenciada por uma série de outros fatores que precisam levados em conta. Assim sendo, e considerando, inclusive, o avanço da ciência na formulação de vários métodos alternativos aos modelos animais, é necessário perquirir se, hodiernamente, é realmente imprescindível impor sofrimento a outros seres vivos para garantir a saúde humana.

\section{REFERÊNCIAS}

BRASIL. Constituição (1988). Constituição da República Federativa do Brasil de 1988. Disponível em: <http://www.planalto.gov.br/ccivil_03/Constituicao/Constituicao.htm>. 
Acesso em: 24 ago. 2018.

BRASIL. Lei n. 11.794, de 8 de outubro de 2008. Planalto. Disponível em: $<$ http://www.planalto.gov.br/ccivil_03/_Ato2007-2010/2008/Lei/L11794.htm>. Acesso em 23 ago. 2018.

BRASIL. Supremo Tribunal Federal, Ação Direta de Inconstitucionalidade 4.983/CE, Requerente: Procurador-Geral da República. Intimados: Governador do Estado do Ceará; Assembleia Legislativa do Estado do Ceará; Associação Brasileira de Vaquejada - ABVAQ. Relator: Min. Marco Aurélio. Brasília, 06 out. 2016. Disponível em: < http://stf.jus.br/portal/diarioJustica/listarDiarioJustica.asp?tipoPesquisaDJ=AP\&classe=ADI\& numero=4983>. Acesso em 30 ago. 2018.

BRASIL. Supremo Tribunal Federal. Recurso Extraordinário n. 153.531/SC. Recorrente: APANDE - Associação Amigos de Petrópolis Patrimônio Proteção aos Animais e Defesa da Ecologia e outros. Recorrido: Estado de Santa Catarina. Relator: Min. Francisco Rezek. Brasília, 03 jun. $1997 . \quad$ Disponível em: $<$ http://www.stf.jus.br/portal/processo/verProcessoAndamento.asp?incidente=1544862>. Acesso em 31 jul. 2017.

BRÜGGER, Paula. Vivissecção: fé cega, faca amolada. In: MOLINARO, Carlos Alberto et al. (Org.). A dignidade da vida e os direitos fundamentais para além dos humanos: uma discussão necessária. Belo Horizonte: Fórum, 2008. p. 145/174.

CASTRO, João Marcos Adede y. Direito dos animais na legislação brasileira: fundamentação e novas perspectivas. Porto Alegre: Sérgio Antônio Fabris, 2006.

DESCARTES, René. Discurso do método. Tradução de Paulo Neves. Porto Alegre: L\&PM, 2016.

FEIJÓ, Anamaria Gonçalves dos Santos. A dignidade e o animal não-humano. In: MOLINARO, Carlos Alberto et. al. (Org.). A dignidade da vida e os direitos fundamentais para além dos humanos: uma discussão necessária. Belo Horizonte: Fórum, 2008. p. $127 / 143$.

FEIJÓ, Anamaria Gonçalves dos Santos; SANTOS, Cleopas Isaías; GREY, Natália de Campos. $\mathrm{O}$ animal não-humano e seu status moral para a ciência e o direito no cenário brasileiro. Revista Brasileira de Direito Animal, Salvador, v. 5, n. 6, p. 153/167, jan/jun. 2010.

FRANCIONE, Gary L. Introdução aos direitos animais: seu filho ou o cachorro? Tradução: 
Regina Rheda. Campinas: Editora UNICAMP, 2013.

FROTA MONT'ALVERNE, T.; ALMEIDA DE ANDRADE, D. O ACESSO JUSTO E EQUITATIVO À BIODIVERSIDADE BRASILEIRA COMO DIREITO FUNDAMENTAL À SAÚDE. Revista Constituição e Garantia de Direitos, v. 4, n. 01, 17 out. 2013.

GOLDIM, José Roberto; RAYMUNDO, Márcia Mocellin. Pesquisa em saúde e direitos dos animais. 2. ed. Porto Alegre: HCPA, 1997.

HAIDT, Jonathan. The emotional dog and its rational tail: A social intuitionist approach to moral judgment. Psychological Review, Washington D.C, 108, p. 814/834, 2001.

HESSLER, Katherine. Fundamentos filosóficos e animais em testes: preocupações e consequências. Revista Brasileira de Direito Animal, Salvador, v. 6, n. 8, p. 65/88, jan/jun. 2011.

HUME, David. Investigação sobre o entendimento humano. Tradução: Alexandre Amaral Rodrigues. São Paulo: Hedra, 2009.

FIGUEIREDO, Guilherme José Purvin de. Curso de direito ambiental. 5. ed. São Paulo: Revista dos Tribunais, 2012.

FRANCIONE, Gary L. Introdução aos direitos animais: seu filho ou o cachorro? Tradução: Regina Rheda. Campinas: Editora UNICAMP, 2013.

KOROBKIN, Russel; ULEN, Thomas. Law and Behavioral Science: Removing the Rationality Assumption from Law and Economics. California Law Review, Berkeley, Vol. $88 / 4$, art. 1, 2000.

KURAN, Timur; SUNSTEIN, Cass R. Availability Cascades and Risk Regulation. Stanford Law Review, Stanford, Vol. 51, n. 4, p. 683/768, 1999.

MELO, Daniela Vieira de. UFRN, P. CONSIDERAÇÕES SOBRE ANÁLISE ECONÔMICA DO DIREITO E A EFETIVIDADE: DIREITO FUNDAMENTAL À SAÚDE NO BRASIL. Revista Constituição e Garantia de Direitos, v. 9, n. 1, p. 156 - 178, 5 out. 2016.

REGAN, Tom. Empty Cages: facing the challenge of animal rights. Maryland: Rowman \& Littlefield Publishers, Inc, 2004. 
RIVERA, Ekaterina A. B. Ética na experimentação animal e alternativas ao uso de animais em pesquisa e testes. In: Ética e bioética aplicadas à Medicina Veterinária.Editado por Ekaterina A. B. Rivera, Maria Helena Amaral, Vladimir P. Nascimento. Goiânia: [s.n.], 2006. p. $159 / 185$.

RODRIGUES, Danielle Tetü. O Direito e os animais: uma abordagem ética, filosófica e normativa. Curitiba: Juruá, 2008.

SANTOLIM, Cesar. "Behavioral Law and Economics" e a teoria dos contratos. CIDP. Disponível em: $<$ http://www.cidp.pt/publicacoes/revistas/rjlb/2015/3/2015_03_0407_0430.pdf >. Acesso em 05 ago.2017.

SARLET, Ingo Wolfgang; FENSTERSEIFER, Tiago. Direito constitucional ambiental: Constituição, direitos fundamentais e proteção do ambiente. 2. ed. São Paulo: Revista dos Tribunais, 2012.

SINGER, Peter. Libertação animal. Tradução: Marly Winckler; Marcelo Brandão Cipolla. São Paulo: WMF Martins Fontes, 2010.

SZTAJN, Rachel. Law and Economics. In: ZYLBERSZTAJN, Decio; SZTAJN, Rachel (Org.). Direito \& Economia: Análise Econômica do Direito e das Organizações. Rio de Janeiro: Elsevier, 2005. p. 74/83.

TRÉZ, Thales. Experimentação animal: um obstáculo ao avanço científico. Porto Alegre: Tomo Editorial, 2015.

\title{
BEHAVIORAL LAW AND ECONOMICS AND THE USE OF ANIMALS IN SCIENTIFIC RESEARCH
}

\begin{abstract}
This paper aims to verify the applicability of some ideas of Behavioral Law and Economics to the decision-making process relating to the use of animals in scientific research, by means of the deductive method and based on a bibliographical review. Behavioral Law and Economics is a derivation from Law and Economics which understands that rationality is limited and that the decision-making process is influenced by heuristics and biases. On the other hand, the
\end{abstract}


use of animal models is an ancient practice in western science, whose option involves moral and scientific features. As to the first, the most important concerns the adequacy of transposing to human beings the results obtained after a research developed with animals. As to the second, the most relevant feature deals with the suffering issue, considering that animals are sentient beings. Weighing up some elements conceived by Behavioral Law and Economics with aspects concerning the decision-making process towards the use of animals in scientific research, one verifies that that process is not purely rational, but it is biased in a way which perpetuates the use of animal models.

Keywords: Behavioral Law and Economics. Animals. Research. 